\title{
Analysis and Comparison of Sensors for Measurements of Partial Discharges in Hydrogenerator Stator Windings
}

\author{
Victor Dmitriev, Rodrigo M. S. de Oliveira, Fernando S. Brasil, Paulo R. M. de Vilhena, \\ Jonathas F. M. Modesto and Ronaldo F. Zampolo \\ Federal University of Pará (UFPA) - 01 Augusto Corrêa street, Belém, Pará, Brazil - CEP 66075-110 \\ E-mails:victor@ufpa.br,rmso@ufpa.br,fernando.brasil@eletronorte.gov.br,paulo.vilhena@eletronorte.gov.br, \\ jonathasfelippe17@gmail.com,zampolo@ieee.org
}

\begin{abstract}
In order to measure electrical signals produced by partial discharges in hydrogenerators stator windings, capacitive couplers are regularly used. They are electrically connected to the windings and therefore, require undesired insulation intrusion. For avoiding such an intrusion, a microstrip directional coupler is used, which is experimentally and numerically investigated in this work. This electromagnetic field sensor is analyzed initially via computer simulation using the finite-difference time-domain method. This numerical analysis is fulfilled considering the coupler placed over a stator bar. Experimental high-voltage tests with generator windings were also performed. We compare the results of the measurements obtained by using various sensors and show that the microstrip directional coupler has some important advantages over traditional capacitive sensors such as complete conductive insulation from the windings and the capacity of detecting shorter PD pulses due to their wider bandwidth.
\end{abstract}

Index Terms - Partial discharges, hydrogenerator stator windings, microstrip directional coupler, high-voltage experiments, FDTD simulations.

\section{INTRODUCTION}

The present-day scenario of the power industry has the predictive maintenance as an indispensable instrument for keeping electricity systems running. This is because the electricity sector is of fundamental importance for today's society. Thus, the power generation equipment must be kept in operation even during maintenance shifts. Partial shut downs should be performed on a scheduled basis, in order to minimize financial losses. The implementation of predictive maintenance aims to migrate from the time-based maintenance to the condition-based maintenance of equipment [1]. Preventive practices are because specific characteristics of fields produced by PD currents can be used to evaluate insulation conditions.

Partial discharges (PDs) are small-localized electric sparks in gases contained in cavities of 
electrical insulators. They are produced by high electric field gradients [2]-[5] across the cavities in insulating material due to regular machine operation voltages. Discharges may or may not occur adjacently to one of the electrodes [5]. The PD pulses contain high-frequency components and they occur in a repetitive manner within the insulation system of high-voltage equipment in operation. In stators of electrical machines, increased PD level or counting can indicate deterioration of winding insulation. PDs can eventually cause the failure of electrical insulation [6].

In [7], approximately $56 \%$ of 69 incidents of fault causes in hydrogenerators were identified to be related to imperfections of insulation sections. In general, constitutive faults (related to design, assembly processes or operational stresses of electrical devices) can be detected and localized by measurement of transient signals originated at PD spots. Thus, PD monitoring procedures have become the most used instrument for determining the condition of stator windings insulation [6].

Capacitive couplers have been used since the 1950s' [5],[8] for measuring signals originating at PD locations [5] because they naturally filter the $50-60 \mathrm{~Hz}$ high-voltage signals of regular machine operation. However, this measuring method compels one to connect electrically the measuring system to stator windings and requires insulation intrusion. This increases chances of machine failures [9]. Along with electrical pulse sensing methods, other approaches have been used, including radiofrequency (RF) radiation sensing, power-factor tip-up and energy/integrated charge transfer [10].

In this context, we design, build and test in this work a microstrip directional coupler used as a nonintrusive PD sensor [11]. This sensor was originally proposed in [12]. We show that the sensor is adequate to experimentally acquire transient signals produced by PDs owing to its wide operating band $(\sim 100 \mathrm{~Hz}-2 \mathrm{GHz})$ and proximity operation features [13] which minimize external interfering signals, as it would happen if antennas were used. The sensor is investigated numerically by FiniteDifference Time-Domain (FDTD) method [14],[15] truncated by using the Convolutional Perfect Matched Layer (CPML) formulation [16], and experimentally by means of a high-voltage equipment with a real hydrogenerator winding bar. We compare several types of sensors used for PD measurements and show that the microstrip directional coupler has important advantages over the traditional capacitive couplers.

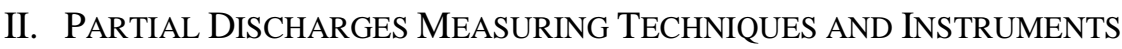

Although partial discharges are associated with several physical manifestations, including electrical pulses and the resulting radio-frequency signals, acoustic pulses, light, as well as chemical reactions involving gases, information provided by electromagnetic fields can be used for assessing the 
condition of insulation of rotating machinery. Classical electrical pulse sensing of PDs consists in measuring small voltage pulses caused by the propagating electromagnetic field or in assessing transient current pulses [2]. Because capacitors present high impedance to the power frequency and low impedance to the high-frequency PD pulses, they are typically part of transfer impedances [5] However, capacitive sensors are frequently connected to the phase terminal or to some other part of the winding, often requiring breaching of insulation.

Electromagnetic waves excited by discharge sparks are not confined and propagate away from the structure. This way, noninvasive near field sensors [2] and RF antennas [18],[19] can be used for detecting PD signals. The electromagnetic disturbance started by a PD contains RF frequencies typically from $100 \mathrm{kHz}$ to several hundreds of megahertz. It is worth noticing that radiated signals are subjected to interference due to fields produced by other sources in a real power generation environment. In addition, multiple field reflections with the structures composing the generation setting significantly alter received transient signals by antennas and complicate analysis of PDs [20]. Consequently, the location of the antenna, the distance to the PD source and the specific bandwidth of the detection system notably influence on the detection sensitivity [3]. Noise influence can be minimized at the expense of substantial narrowing of the received signal bandwidth, yielding loss of information [20].

In this context, directional couplers [13] (Fig.1) are an attractive solution. Directional couplers can usually work with frequencies ranging from several Hertz to approximately $10 \mathrm{GHz}$ [2]. This kind of sensor needs to be installed as close as possible to that part of the winding, which may be most exposed to critical PD activity. Figures 1 and 2 show directional couplers designed and constructed in our work. They consist of a microstrip-based structure, formed by a main conducting strip, separated from the ground plane by a dielectric substrate. The conducting strip and the ground plane are connected by a $50 \Omega$ resistor $R$ (Fig.2), used for impedance matching with the used cable and for absorption of reflected signals. The resistor is also used for reduction of external interfering signals. The other end of the coupler is connected to a coaxial cable (Fig.1a), which in turn is connected to an oscilloscope. This device can be manufactured using simple printed circuit board (PCB) technology. 


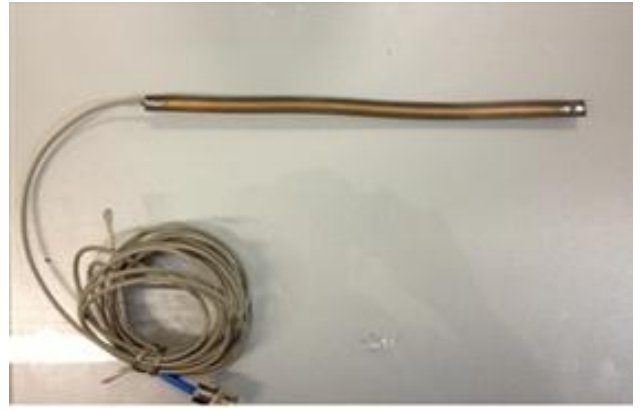

(a)

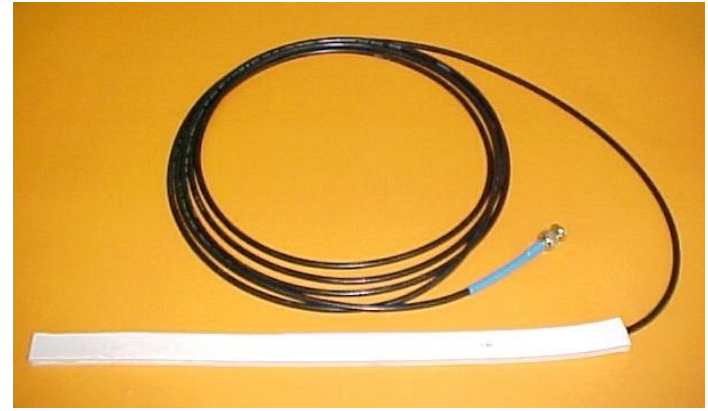

(b)

Fig.1. Duroid-based microstrip directional coupler sensor: (a) without encapsulation, (b) sensor encapsulated in silicon.

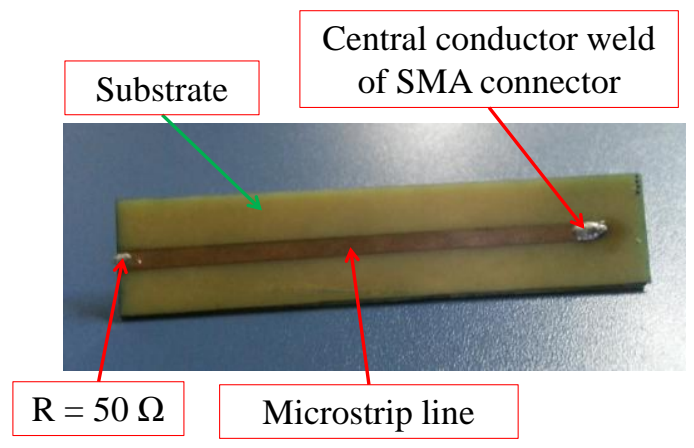

(a)

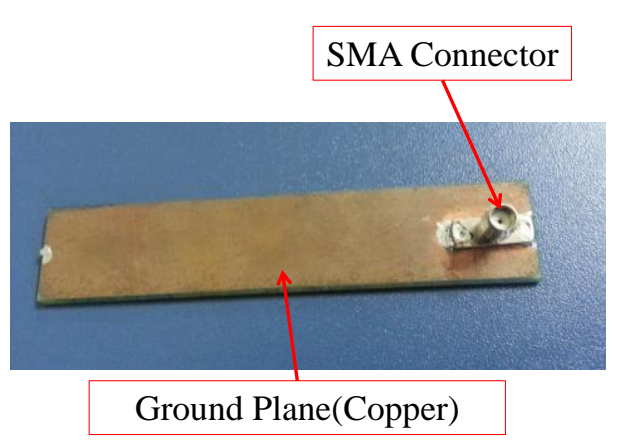

(b)

Fig.2. Details of directional coupler: a) top view, b) bottom view.

\section{NUMERICAL AND EXPERIMENTAL ANALYSIS OF THE MICROSTRIP DIRECTIONAL COUPLER}

For performing numerical investigation, we employed the SAGS (synthesis and analysis of grounding systems) [21] parallel electromagnetic simulator, adapted specially in our work for modeling partial discharges (see Appendix A) via the FDTD method. This approach is used to solve Maxwell's equations numerically in time domain with finite differences [14],[15]. The structure investigated experimentally in [14] was numerically reproduced in our work for validation of the numerical analysis. As shown in Appendix A, our numerical results agree very well with PD experiments in literature.

The directional coupler was designed with the following dimensions: $10 \mathrm{~cm}$ (length), $2 \mathrm{~cm}$ (width) and $1.5 \mathrm{~mm}$ (thickness). The coupler conducting strip is $9 \mathrm{~cm}$-long and $4 \mathrm{~mm}$-wide. It is connected by a subminiature version A (SMA) connector (Fig.2b) to the oscilloscope through a coaxial cable (Fig.1). The substrate dielectric material is duroid. With this sensor, one can register the PD signals without 
electrical contacts with winding coil and minimize interference caused by external electromagnetic field sources. The experimentally measured return loss of the coupler is shown by Fig.3, where we can see that the first resonance occurs at approximately $547 \mathrm{MHz}$. As far as the substrate relative permittivity is about 2.2 , a wavelength of approximately $37 \mathrm{~cm}$ is obtained. Notice that the calculated wavelength is about four times the length of the coupler, as predicted in [22]. In addition, as described in [23], all other resonances can be calculated by multiplying the first resonance frequency by an odd integer. This feature can also be seen in Fig. 3.

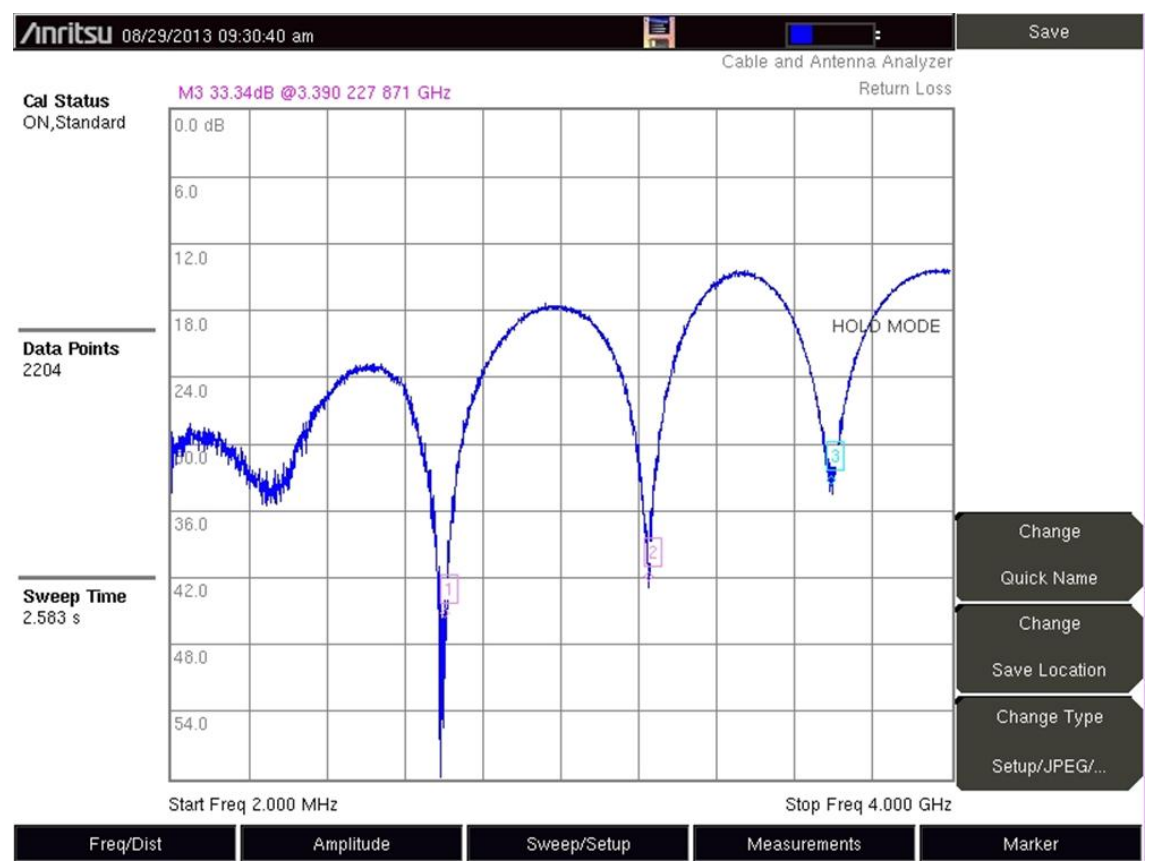

Fig.3. Measured return loss of our constructed directional coupler.

In order to validate results in Fig. 3 and our FDTD simulator, we have conceived a numerical model of the directional coupler (Fig.4). We have set the edge of cubic Yee cells [24] to $\Delta x=\Delta y=\Delta z=2$ $\mathrm{mm}$, allowing us to simulate the coupler along with the hidrogenerator bar by reducing computational resources requirements. The coupler's microstrip line and ground plane were modelled by setting tangential electric field components ( $E_{x}$ and $E_{y}$ ) to zero on Yee's cells faces (Fig.4(b)), which is the usual FDTD representation of perfect electric conductor thin sheets [15]. This representation is valid only when $\Delta x, \Delta y$ and $\Delta z$ are smaller than $\lambda_{\min } / 10$. For this reason, these metallic flat surfaces have a discrete (gridded) representation in their equivalent FDTD model illustrated by Fig.4.

Simulations were executed in a Beowulf cluster [25] with 16 quadcore computers (64 processing cores were used). The numerical model of the coupler is $10 \mathrm{~cm}$-long, with $2 \mathrm{~cm}$ in width and the dielectric substrate (Duroid) has the following parameters [26]: $\epsilon_{r}=2.2, \sigma=1.0 \times 10^{-9} \mathrm{~S} / \mathrm{m}, \mu_{r}=1$ and dielectric strength of $11.2 \mathrm{kV} / \mathrm{mm}$. The strip is $9 \mathrm{~cm}$-long and $4 \mathrm{~mm}$-wide. The output port pin 
extends from the strip to the coupler's connection port, such as indicated in Fig.4. Coupler's output signal is the voltage induced between the port pin and the ground plane. Notice that using the method described in [27] one obtains the impedance of the coupler approximately of $54 \Omega$.

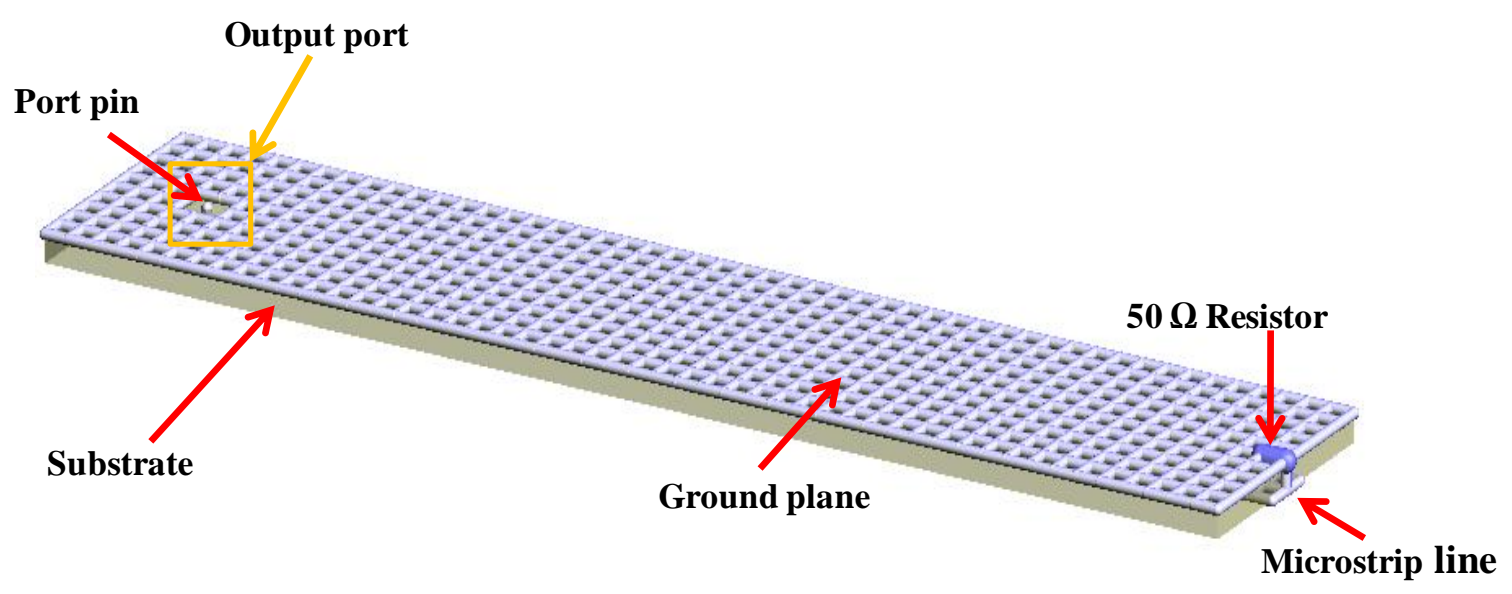

(a)

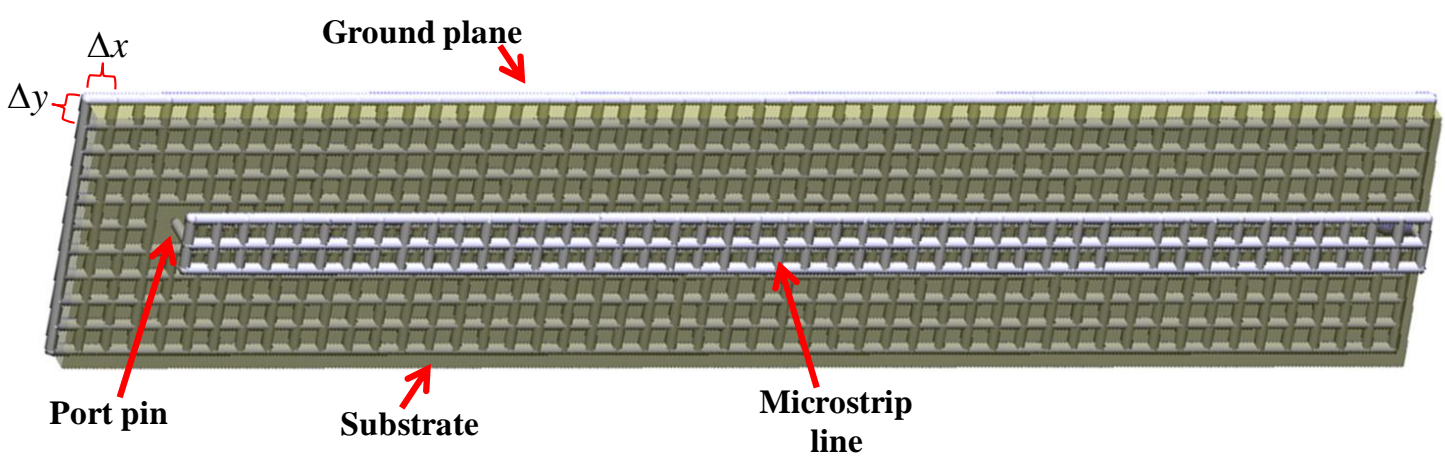

(b)

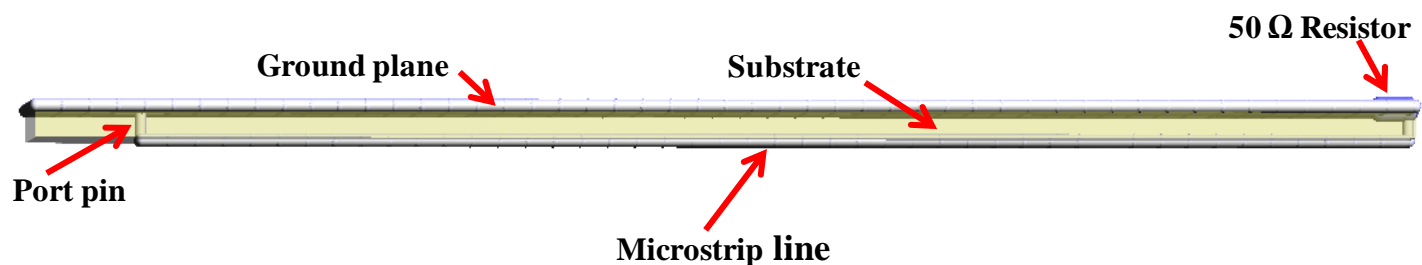

(c)

Fig.4. FDTD model of the directional coupler as viewed in SAGS: (a) top view, (b) bottom view and (c) side-view.

The return loss of the coupler was calculated numerically via FDTD method and measured experimentally (Fig.5). Notice that it is below $-14 \mathrm{~dB}$ from $\sim 100 \mathrm{~Hz}$ to $2 \mathrm{GHz}$. One can see a good 
agreement between the measurements and the FDTD simulation results.

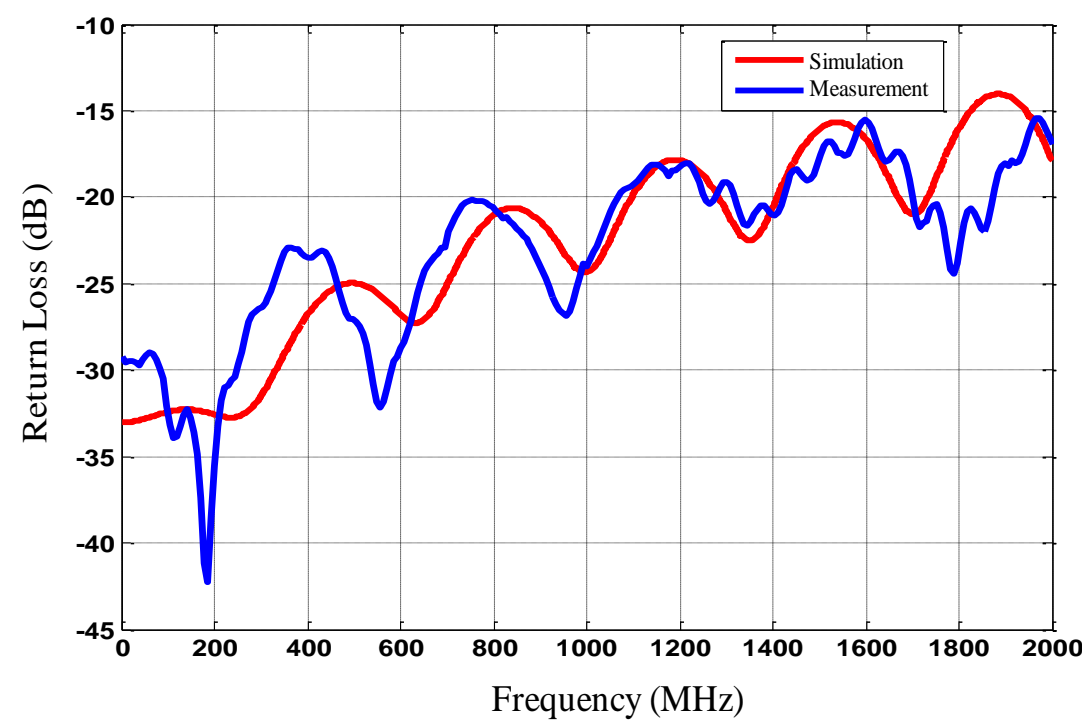

Fig.5. Simulated (FDTD) and measured return loss (dB) of the microstrip directional coupler.

For verification of physical consistence of results obtained with the directional coupler placed on the $3.5 \times 0.066 \times 0.022 \mathrm{~m}$-bar, the simulation performed to validate the software SAGS (described in Appendix A - Fig.16) is repeated. However, for the present simulation, the FDTD numerical model of the directional coupler is placed over the structure, as illustrated by Fig.6, inset 1. The insets 2 and 3 in Fig.6 show the excitation port, which was conceived for ensuring impedance matching between the bar's metallic core and the voltage excitation source. Notice that grounding system of electrodes was modeled by penetrating part of the metallic structure in conductive soil with the parameters $\varepsilon_{\mathrm{r}}=10$ and $\sigma=10 \mathrm{~S} / \mathrm{m}$. In order to represent ground as a semi-infinite medium, the soil model penetrates the CPML walls and waves are absorbed. Reflections are avoided by ensuring impedance matching between CPML and soil and between CPML and free space [16] [21]. The resistor in insets 2 and 3 of Fig.6 performs the same function of that in Fig.16 (b) [28] (observe that both of them are placed at the same location). The inset 4 in Fig.6 shows the output port. Output voltage is calculated between the grounded electrode and the inner conductor. 


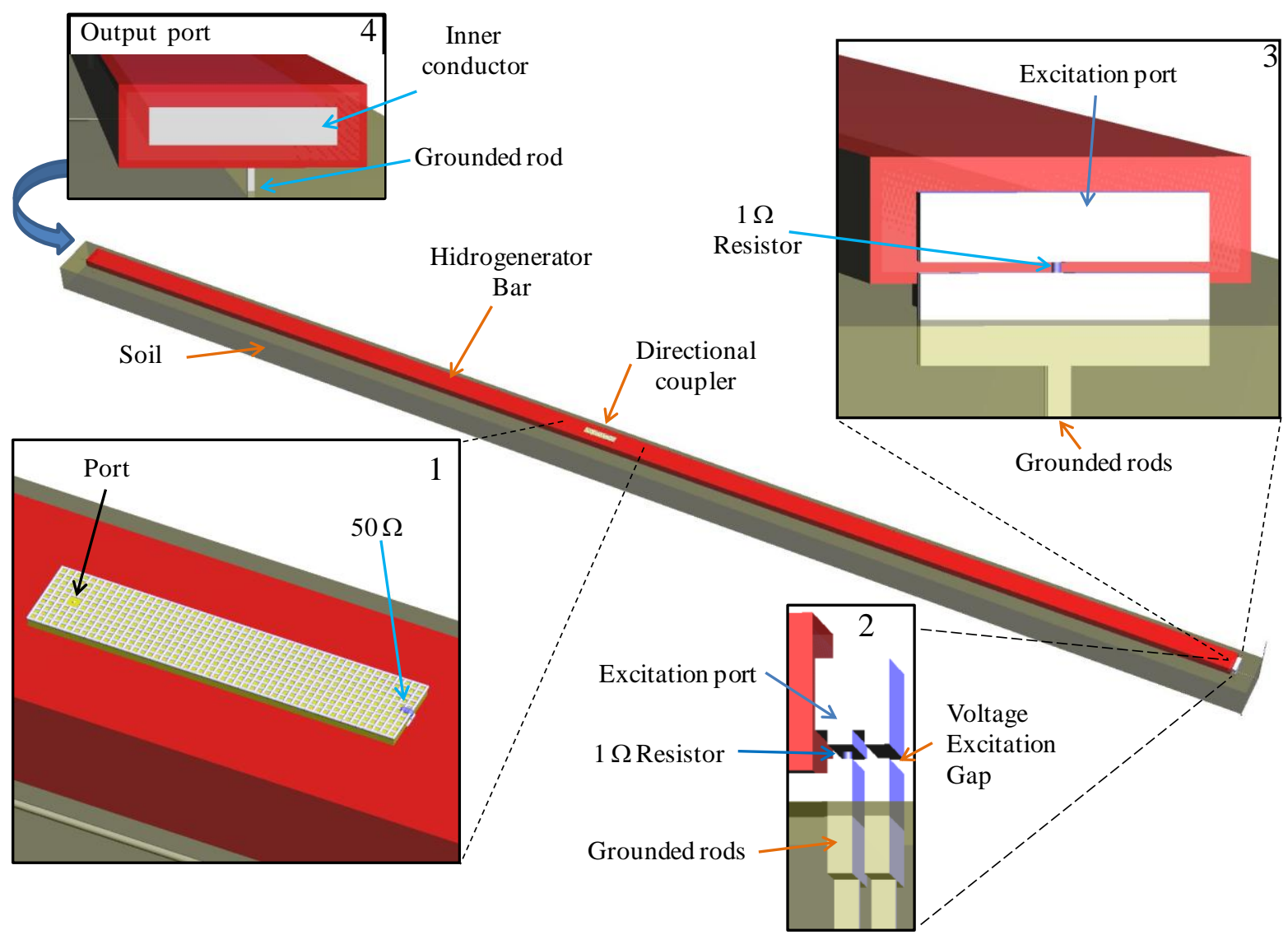

Fig.6. SAGS FDTD model of the directional coupler on the bar modeled for validation of measurements: inset 1: the directional coupler; inset 2: excitation port and grounded rods; inset 3: excitation port (front view); inset 4: output port [28], grounded rod and bar inner conductor (output voltage is obtained between inner conductor and grounded rod). Every grounded structure partially penetrates soil.

The (normalized) signal obtained at the coupler's port is shown in Fig.7. The signal shape is very similar to the time derivative of the signal of Fig.17, which is obtained at output port (inset 4 of Fig.6). This effect is expected because the coupler is much smaller than the minimum signal's wavelength $\left(\lambda_{\min } \approx 38 \mathrm{~m}\right)$ [27]. It is interesting to notice that the oscillations seen in Figs.7 and 20 are caused by reflections at the bar ends (each peak is registered after the wave propagated through the bar length two times), producing specific resonance. In comparison to the signal of the bar output port A, a significant reduction of the signal level registered by the directional coupler is observed. It is mainly a consequence of the shielding effect caused by the bar metallic coating (Fig.16), over which the coupler is placed. However, bandwidth of directional couplers is much larger than that of capacitive couplers, as shown in the next Section. Coupling factor between the directional coupler and the Roebel bar and a discussion concerning its directivity are presented in Appendix B. 


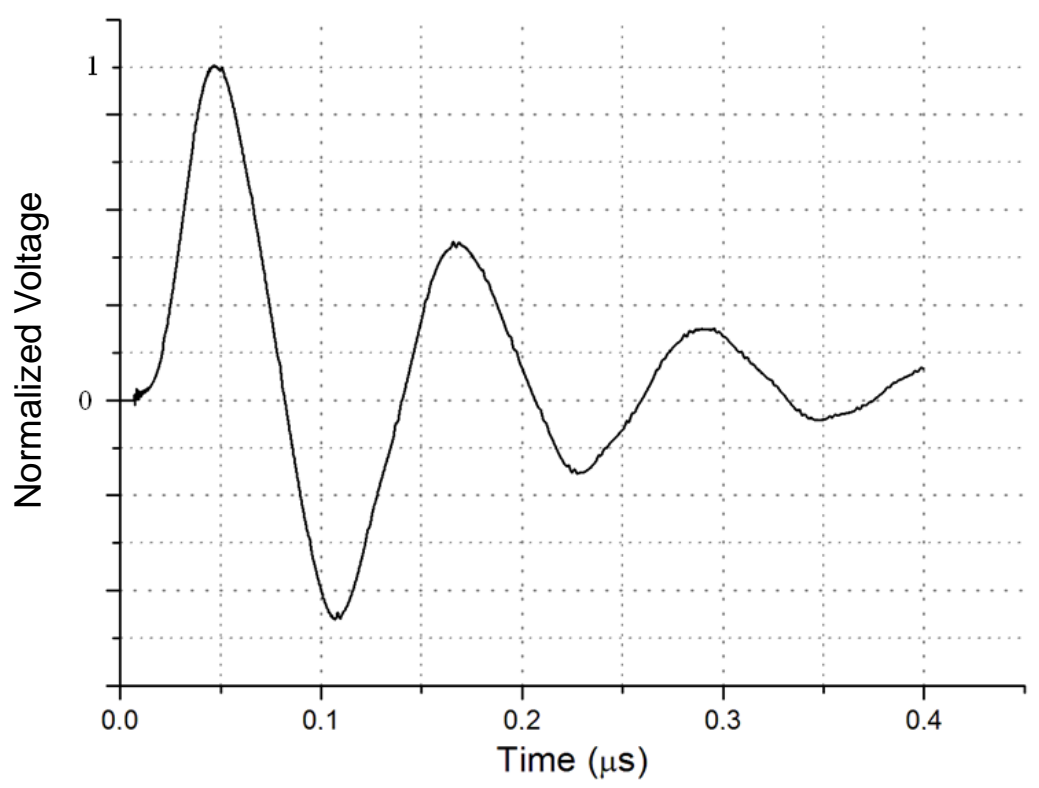

Fig.7. Signal induced on the directional coupler, obtained numerically by modelling the bar with the sensor.

\section{HIGH-VOLTAGE PARTIAL DISCHARGE EXPERIMENTS}

In order to analyze PDs in the stator windings, experiments were performed in a laboratory with an imbricated type Roebel bar, which is 2.9 m long, removed from a 290 MW hydrogenerator. Fig.8(a) shows the high-voltage experimental set up in Eletronorte HV-laboratory. The transfer impedance [5] is a coupling device that converts the input currents to the output voltage signals (schematics are given by Fig.8(b)). These signals are transmitted to the measuring device. The coupling capacitor $C_{1}$ in Fig.8(b) is used as a sensor for detecting PD signals from the machine winding. In experiments, $100 \mathrm{kV} 60 \mathrm{~Hz}$-source from Instronic was used. The transfer function $H(\omega)$ of the transfer impedance circuit in Fig.8(b), considering ideal lumped circuit elements, is given by [5]

$$
H(\omega)=\frac{j \omega C_{1} R}{j \omega\left(C_{1}+C_{2}\right) R+1}
$$

For data collection, two measuring systems were used: the Monitoring and Partial Discharge Measuring Device (IMA-DP) produced by CEPEL (Electrical Energy Research Center, in Brazil) and a Tektronix digital oscilloscope 3034B $(350 \mathrm{MHz}-2.5 \mathrm{GS} / \mathrm{s})$. The former was used during experiments for recording PRPD (phase-resolved partial discharge) map of partial discharges. It consists of software and hardware (particular oscilloscope) parts. The latter instrument was used to record the DP signals in time domain. 


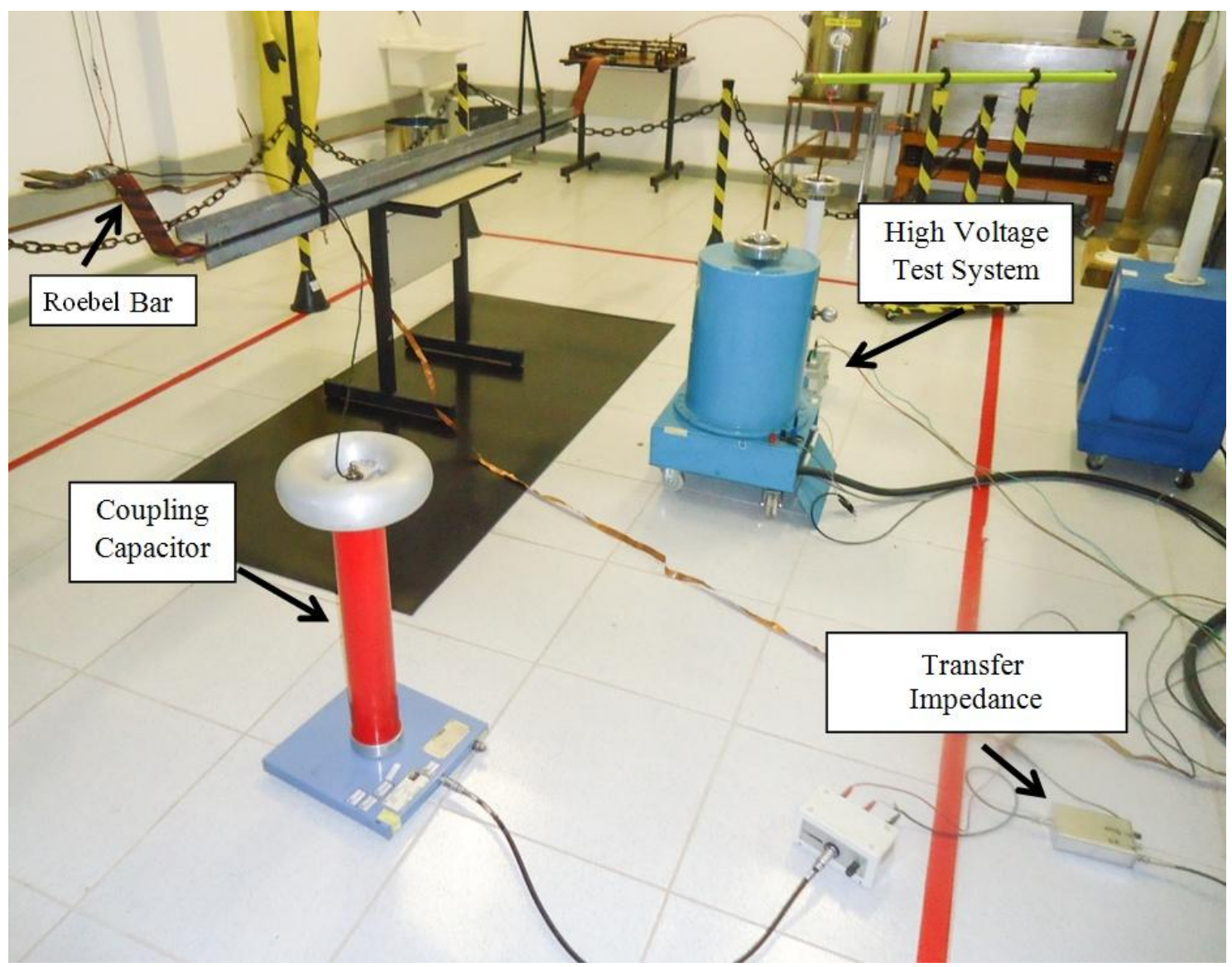

(a)

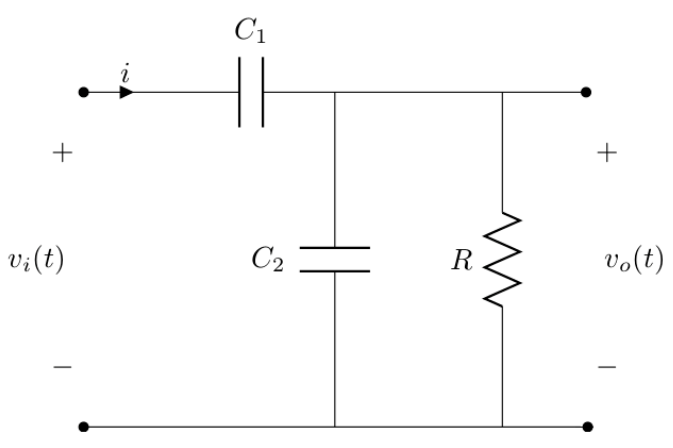

(b)

Fig.8. The high-voltage experiment: (a) setup at Eletronorte laboratory and (b) schematics of the transfer impedance $\left(R_{-}=\_2\right.$ $\mathrm{k} \Omega$ and $C_{2}=0.132 \mathrm{nF}$ ) connected to coupling capacitor $C_{1}$.

Two traditional capacitive couplers of 80 and $220 \mathrm{pF}$ and a microstrip directional coupler were tested. The directional coupler was put in the winding slot of the Roebel bar (and not over the winding metallic structure), as indicated in Fig.9. For safety purposes, a measurement impedance of $2000 \Omega$ was connected between the directional coupler and the oscilloscope for each measurement performed. 
Notice that the transfer impedance was used with the capacitive couplers only.

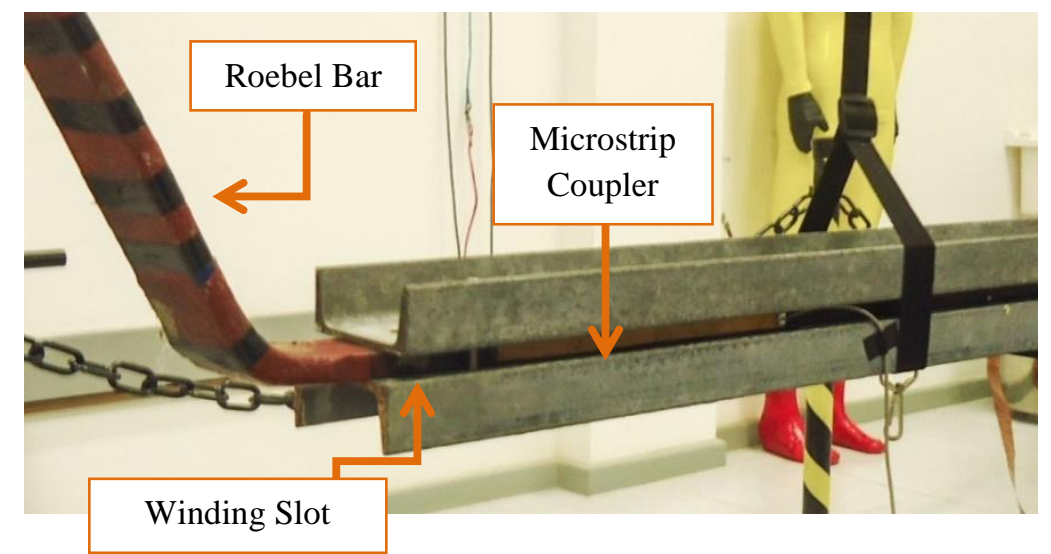

Fig.9. The directional coupler installed in winding slot for registering PD signals in a Roebel bar.

Acquisition and analysis of signals have been performed using IMA-DP and a 2.5 GigaSamples/second oscilloscope. The software separates PD signatures from the $60 \mathrm{~Hz}$ power signals, from noise and other disturbance sources. Signals are then filtered and PD peak values are estimated, recorded and finally plotted along with the phase of $60 \mathrm{~Hz}-$ power signal.

The high-voltage tests were performed using the methodology defined by IEC [4]. The procedure starts with the application of a $60 \mathrm{~Hz}$ gradually increasing voltage from zero to the conditioning voltage $U_{n}=13.8 \mathrm{kV}$, which is applied during five minutes (Fig.10). Voltage is then progressively reduced to zero. Subsequently, the voltage is slowly raised to $U_{n} / \sqrt{3}$ and the first measurements and recording of the PD patterns are conducted during an acquisition time interval of 60s (Fig.10). The voltage is progressively raised back to $U_{n}$ and PD counting is carried out for another minute. This methodology is used because PD counting is affected (it is typically smaller) during the first minutes of high-voltage application, as accurately detailed in [4]. The presented conditioning procedure ensures steady PD activities in the winding component to be measured.

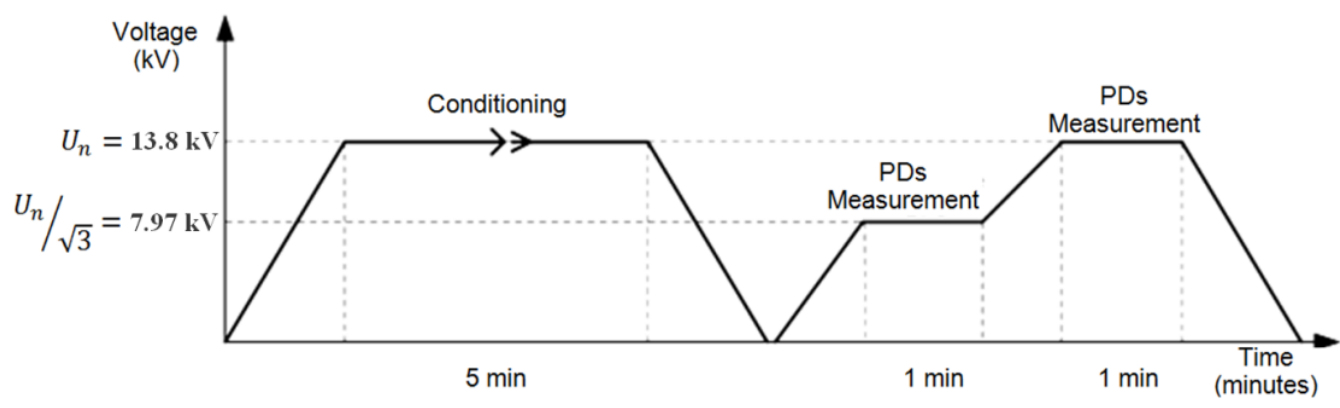

Fig.10. Outline of $60 \mathrm{~Hz}$ high-voltage application during time for conditioning the bar and registering PD data.

During the high-voltage measurements with the capacitive couplers, we observed the excitation of the first DPs when $60 \mathrm{~Hz}$ voltage reached approximately $10 \mathrm{kV}$. Figs.11(a) and (b) show the graphs resulted from a phase-resolved partial discharge (PRPD) analysis (also known as Pulse Phase 
Analysis - PPA [29]) for the coupling capacitors of $80 \mathrm{pF}$ and $220 \mathrm{pF}$, respectively, with the applied voltage of $13.8 \mathrm{kV}$ (Fig.10). PRPD pattern graphics are constructed by plotting PD peak values as function of power signal phase and by mapping frequency of occurrence of a given PD peak value to a color map. In Figs.11(a) and (b), blue color represents low frequencies of PD occurrence and green and yellow represent intermediate and high frequencies of PD occurrence, respectively. In Fig.12, lighter red indicates high frequencies of PD occurrence. For counting partial discharges during measuring period, a threshold value of one fifth of the maximum PD peak registered for a particular sensor under test is used.

It is observed from data in Figs.11-14 and from Table I that the 80 pF-based sensor presents reduced measurement sensitivity when compared to the $220 \mathrm{pF}$-based sensor. Although the frequency spectra of $80 \mathrm{pF}$ and $220 \mathrm{pF}$ presents higher energy density of measured signals in the range from a few Hertz to approximately $10 \mathrm{MHz}$ (Figs.13(b) and (d)) and small energy density was observed to be distributed in the range of 30 to $50 \mathrm{MHz}$ for the $80 \mathrm{pF}$ sensor, IMA-DP registered 1066 PD pulses with the 80pF-based measuring circuit (during 60 seconds) and 1413 pulses with the $220 \mathrm{pF}$ coupler (Table I). This behavior, which has been verified several times during experiments, is attributed to the fact that the capacitors and other components of transfer impedance are not ideal. In addition, the comparison of dimensions of the capacitors to the wavelengths of the tens of megahertz range makes it clear that the sensors can hardly be considered lumped circuit elements. This factual condition produces transfer functions different from the ideal curves shown by Fig.14, affecting experimental results. Finally, as predicted in Fig. 14, the maximum average peak registered with the $80 \mathrm{pF}$ sensor $(90 \mathrm{mV})$ is smaller than the $160 \mathrm{mV}$ observed with the $220 \mathrm{pF}$ capacitor (Table I).

The PRPD measured with both capacitive couplers presented a specific level of symmetry for positive and negative discharges with respect to the negative and positive half cycles. This pattern is compatible to the standard shown in [3] for internal partial discharges obtained with capacitive couplers.

TABLE I. Characteristics of partial discharges and corresponding systems.

\begin{tabular}{|c|c|c|c|c|c|}
\hline \multicolumn{2}{|c|}{} & $\begin{array}{c}\text { Absolute average } \\
\text { peak amplitude of } \\
\text { Megistered PD } \\
\text { signals (mV) }\end{array}$ & Number of Registered Pulses & \multicolumn{2}{|c|}{ Theoretical Cutoff Frequencies } \\
\cline { 3 - 5 } & $\begin{array}{c}\text { IMA-DP with } 80 \\
\mathrm{pF} \text { coupling } \\
\text { capacitor }\end{array}$ & 90 & 1066 & 995.22 & 31.00 \\
\hline 1 & $\begin{array}{c}\text { IMA-DP with } \\
220 \mathrm{pF} \text { coupling } \\
\text { capacitor }\end{array}$ & 160 & 1413 & 361.90 & 30.36 \\
\hline 3 & $\begin{array}{c}\text { Microstrip } \\
\text { directional }\end{array}$ & 25 & 2084 & 0.10 & 1000.00 \\
\hline
\end{tabular}




\begin{tabular}{|c|c|l|l|l|l|}
\hline & coupler with & & & & \\
oscilloscope & & & & \\
Tektronix & & & & \\
\hline
\end{tabular}

The second step of the $13.8 \mathrm{kV}$ experiment was conducted in order to evaluate the performance of the microstrip directional coupler. The obtained PRPD pattern is shown in Fig.12 and average temporal and spectral signals are shown in Figs. 13(e) and 13(f). It is important to notice that the measurements performed with the directional coupler registered PDs in a spectral range from tens of Hertz to $400 \mathrm{MHz}$, with most of energy distributed over the range $100 \mathrm{~Hz}$ to $280 \mathrm{MHz}$, a bandwidth much wider than observed in Figs. 13(b) and 13(c) for capacitive couplers PD signals, as predicted by return losses in Fig.5. This means that PD information in the band from $10 \mathrm{MHz}$ to $280 \mathrm{MHz}$ is neglected by capacitive systems. This fact suggests that discharges with smaller rise times are not accounted in PRPD analysis performed with capacitive couplers. This assumption was confirmed in our experiments, as far as 2048 PDs (Table I) have been detected when directional coupler was used. The improvements on spectral bandwidth and PD counting results are obtained at the expense of reducing amplitude of received signals, as shown in Table I.

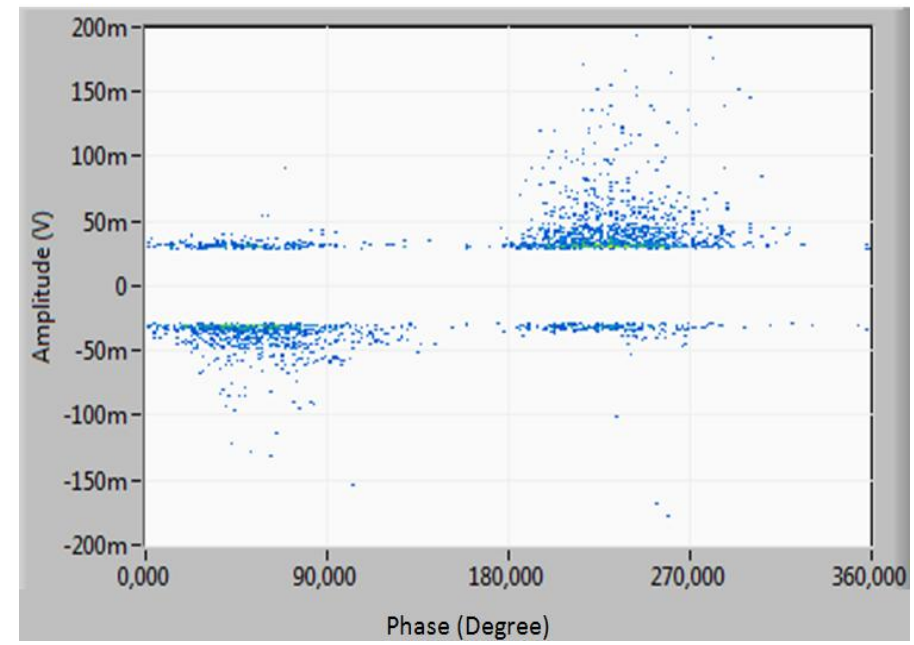

(a) 


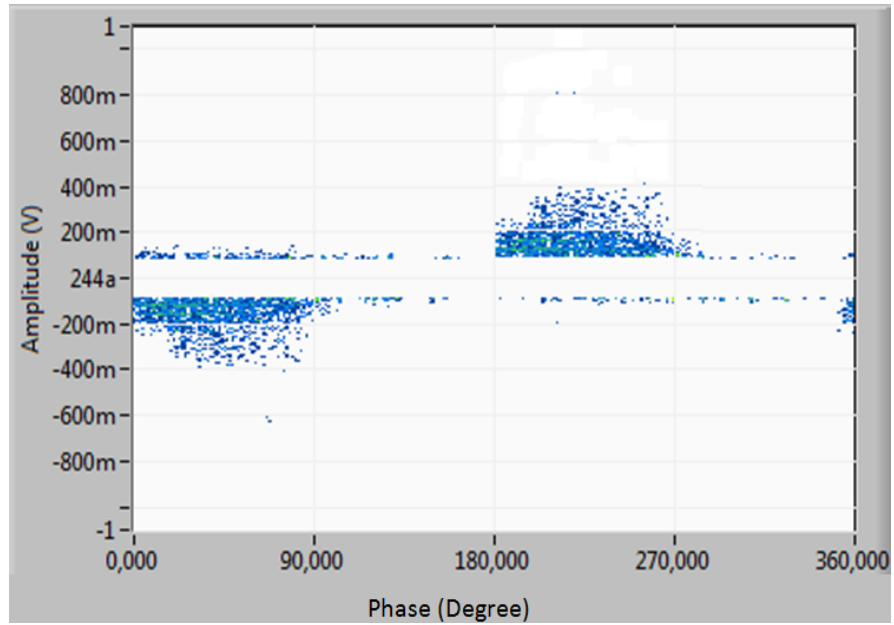

(b)

Fig.11. PRPD pattern (with respect to the $60 \mathrm{~Hz}$ AC cycle) obtained with capacitive couplers by subjecting the Roebel bar to $15 \mathrm{kV}$ : (a) $80 \mathrm{pF}$ and (b) $220 \mathrm{pF}$.

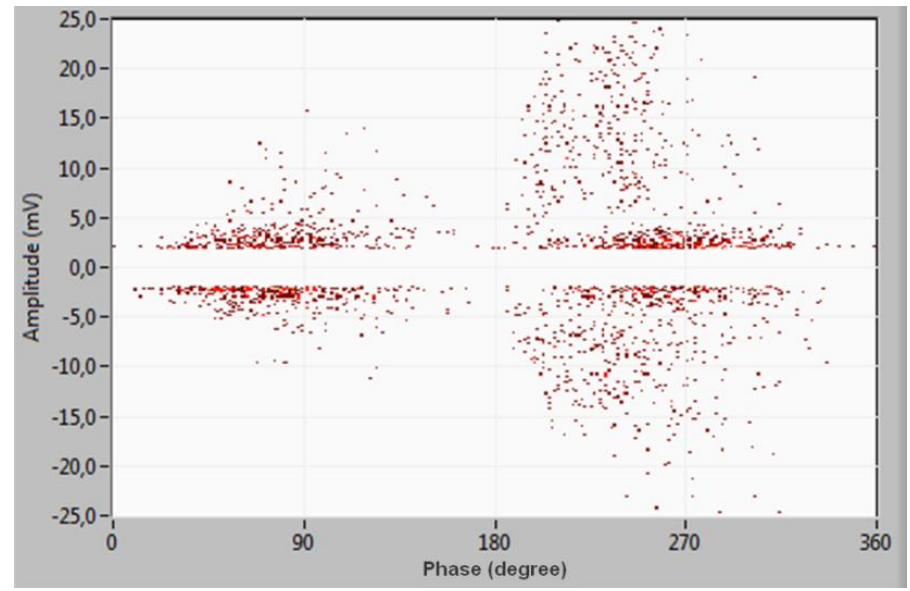

Fig.12. PRPD pattern (with respect to the $60 \mathrm{~Hz}$ AC cycle) obtained by using the microstrip directional coupler. 

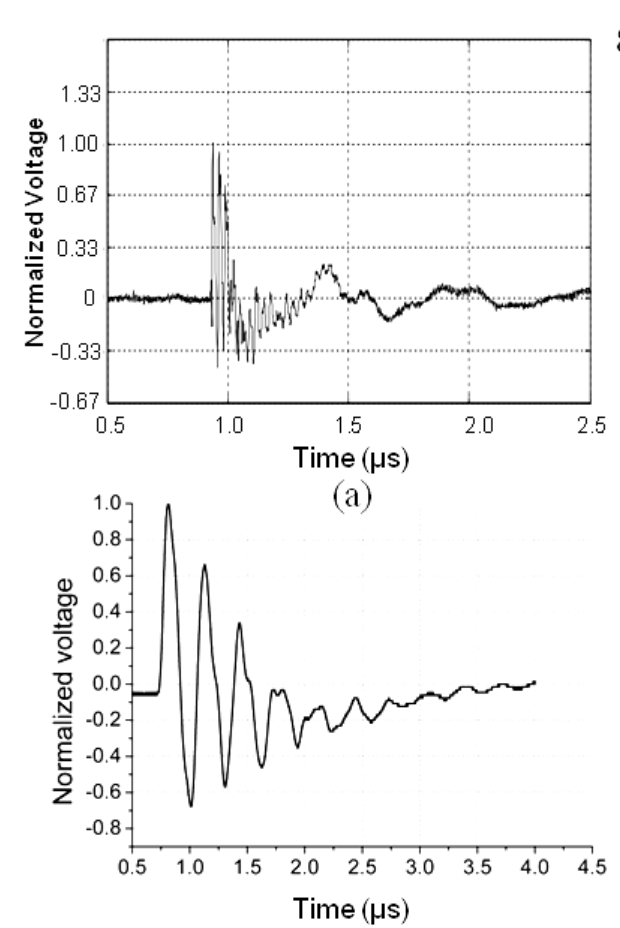

(c)

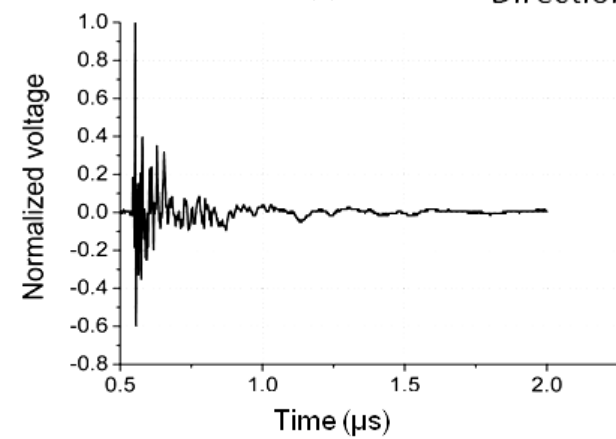

(e)

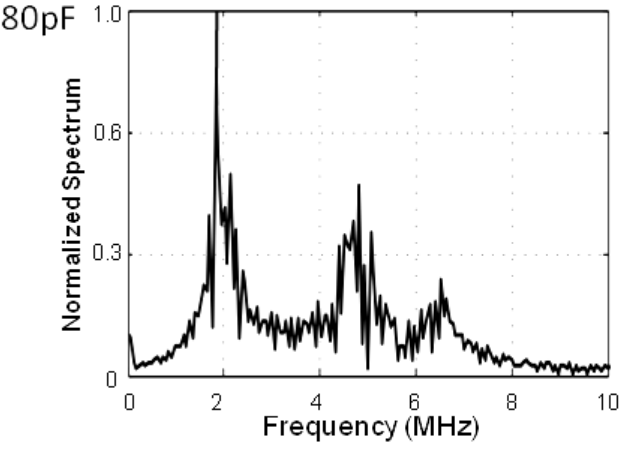

(b)

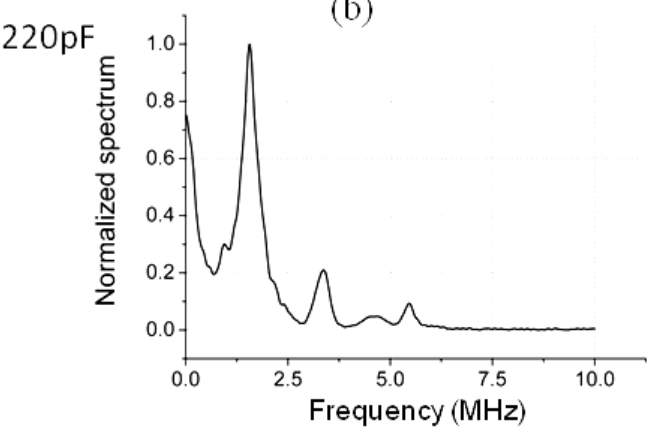

(d)

Fig.13. Averaged PD signals in time and frequency domains acquired with various measuring systems during the $13.8 \mathrm{kV}$ high-voltage experiment: (a) and (b) for $80 \mathrm{pF}$ capacitive coupler; (b) and (c) for $220 \mathrm{pF}$ capacitive coupler; (e) and (f) for microstrip directional coupler. 


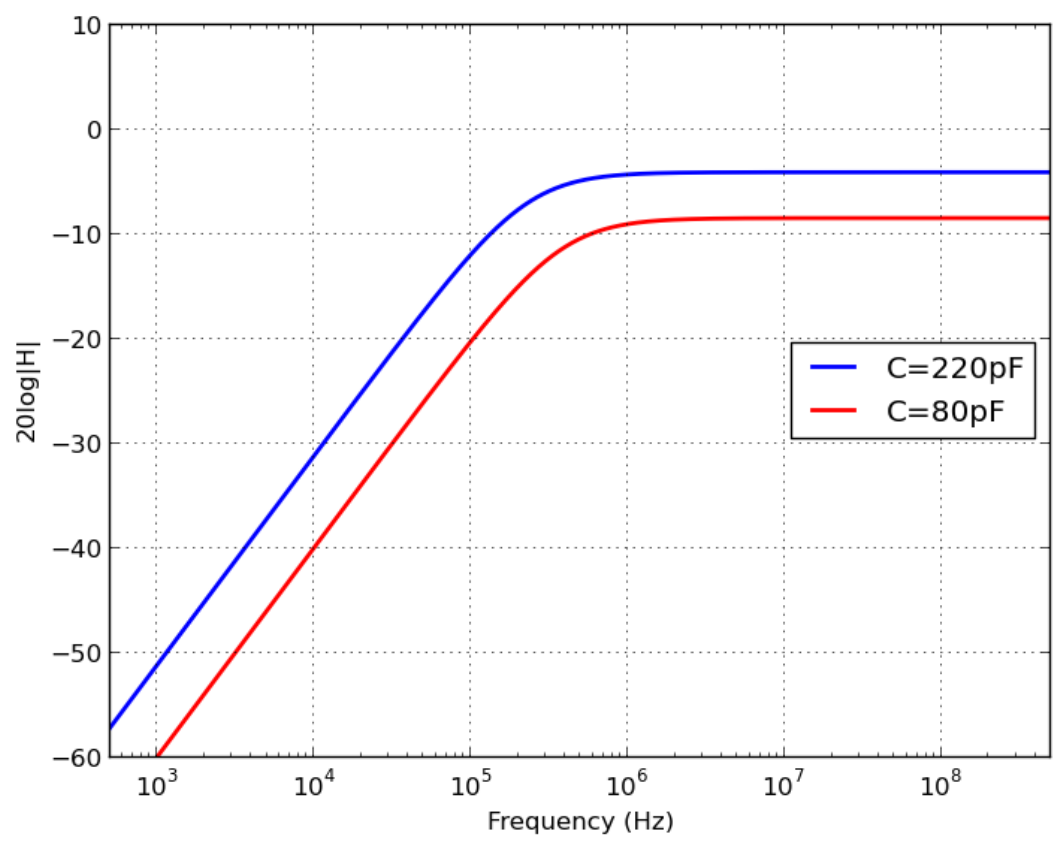

Fig.14 Theoretical absolute values of the transfer function of the transfer impedance with coupling capacitors $C_{1}$ of $80 \mathrm{pF}$ and $220 \mathrm{pF}$.

\section{FInAl REMARKS}

In this work, we have analyzed and compared experimental techniques for measuring partial discharges signals in the stator windings of hydrogenerator. For the study of different sensors, it was assembled in laboratory a high-voltage experimental setup. Conventional capacitive couplers of 80 and $220 \mathrm{pF}$ used in most power plants and a directional coupler were tested and compared. Our experimental results show that the measurement of partial discharges signals by using directional couplers presents some advantages in comparison with the conventional capacitive couplers.

It is naturally observed that different sensors possess different bandwidths and different amplitude sensitivity levels of PDs. The main advantage of the directional coupler when it is used as a PD measuring device is a higher precision of pulse counting as compared with traditional capacitive couplers. As we have shown in the paper, the traditional capacitive couplers reject a significant part of the high-frequency band of PD signals, affecting PD counting. On the other hand, directional couplers with their greater bandwidth, can account for shorter pulses in comparison with the capacitive couplers. In addition, the directional couplers are less sensitive to the noise produced by remote sources, because they are very close to the bars. Thus, the use of the directional couplers as PD sensors allows one to improve PD counting due to the possibility to detect short pulses which the 
capacitive couplers reject by filtering.

It is noteworthy that all couplers evaluated in the high-voltage experiments were able to register partial discharges when the bar was subjected to a voltage of $13.8 \mathrm{kV}$. The capacitive couplers are efficient for detecting discharges with spectral energy from a few $\mathrm{Hz}$ to tens of megahertz and the directional couplers registered PD pulses with energy distributed on a much wider spectral range from $100 \mathrm{~Hz}$ to $280 \mathrm{MHz}$. Notice that pulses with frequency components from $100 \mathrm{MHz}$ to $280 \mathrm{MHz}$ can present very significant amplitudes (between 10 to 60 percents of maximum spectral amplitude). This way, as far as the directional coupler tends to preserve the PD pulse shapes with smaller rise times (as shown in FDTD simulations) and due to the fact that it works only from very small distances from object under test, the PD counting procedure based on directional couplers is more precise than PD counting performed with capacitive couplers. It was experimentally demonstrated in our work.

\section{APPENDIX A: VALIDATION OF EXPERIMENTS VIA COMPUTATIONAL SIMULATIONS}

For purposes of validation of our experiments, the software SAGS [21] which solves Maxwell's equations by the finite-difference time-domain method (FDTD-3D), was adapted by authors for modeling partial discharges. We reproduced the results of the problem investigated in [28], where experiments were conducted to study the propagation of PD signals along stator bars. These experiments were carried out in a 3.8m-long sample bar (of Roebel type) dismantled from a 900MW generator. Voltage V1 was applied to the bar input and voltage V2 was measured at the output. Fig.15 shows the experimental setup used in [28], which was numerically reproduced in our paper.

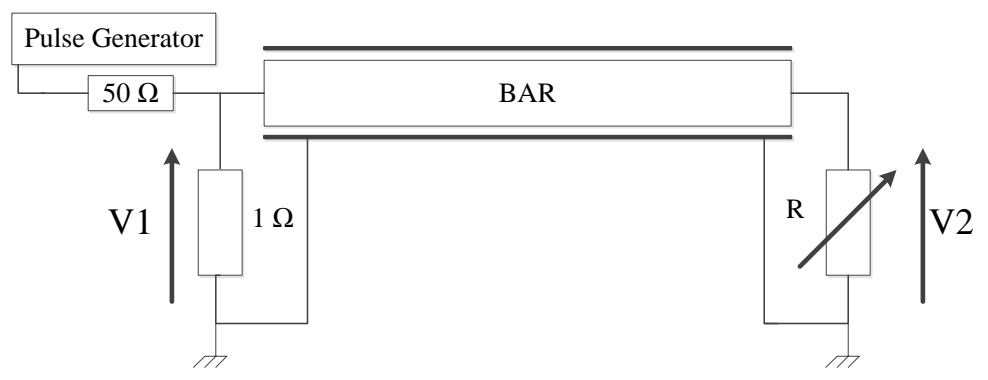

Fig.15. Circuit used experimentally in [28], which is reproduced numerically in this work.

The FDTD numerical model is composed of three layers: inner metal structure, surrounded by a dielectric layer, which in turn is coated with an outer metallic layer, as illustrated by Fig.16. The dielectric layer made of mica is characterized by the parameters $\varepsilon_{\mathrm{r}}=3.8, \sigma=0.00010394 \mathrm{~S} / \mathrm{m}$ and $\mu_{\mathrm{r}}=$ 1. Metallic parts are considered to be copper $\left(\varepsilon_{\mathrm{r}}=1, \sigma=10270 \mathrm{~S} / \mathrm{m}\right.$ and $\left.\mu_{\mathrm{r}}=1\right)$. It is worth mentioning 
that these parameters were inferred from the results presented by [28]-[30] and by measurements performed on a similar bar provided by Eletronorte. The parameters used are in accordance with the parametric ranges specified in [31] and [32] for mica and cooper, respectively.

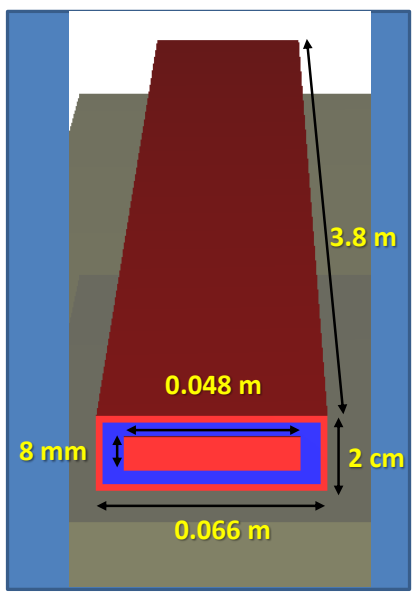

(a)

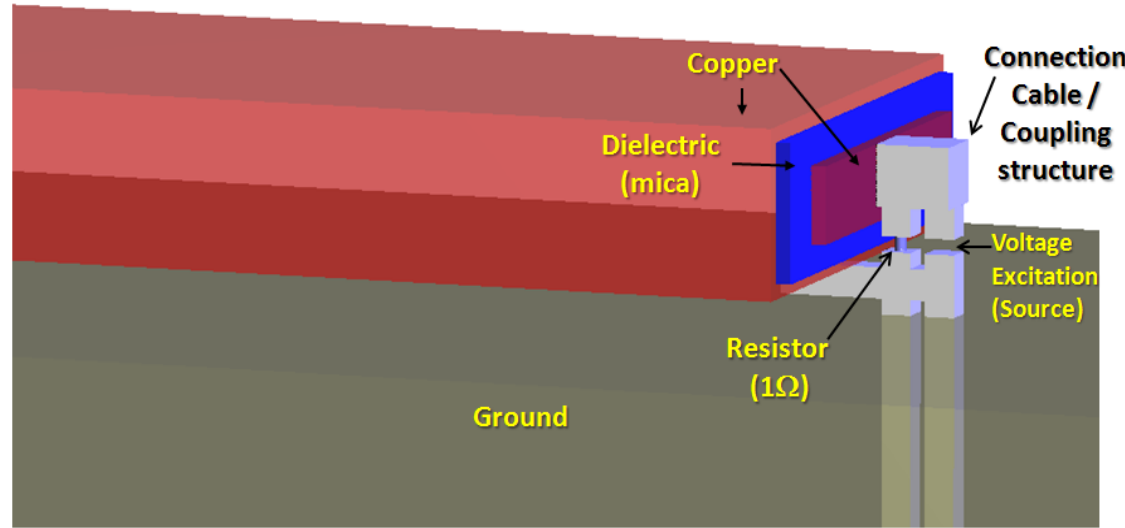

(b)

Fig.16. FDTD model of the bar as displayed by SAGS: dimensions and 3D representation.

The rectangular FDTD grid created to represent the space consists of $848 \times 254 \times 165$ cubic Yee cells, with edge $\Delta=2 \mathrm{~mm}$. Certain approximations have been made in the structure's numerical model, since not all geometric data were specified in [28]. It was found that the diameter of the connecting cables significantly contributes to the output voltage V2. Cables with diameter smaller than $8 \mathrm{~mm}$ caused additional oscillations in the result. Lumped elements were modeled by using formulation presented in [24]. A comparison between the waveforms of voltage V2, obtained from FDTD simulation and from experiments in [28], is shown in Fig.17.

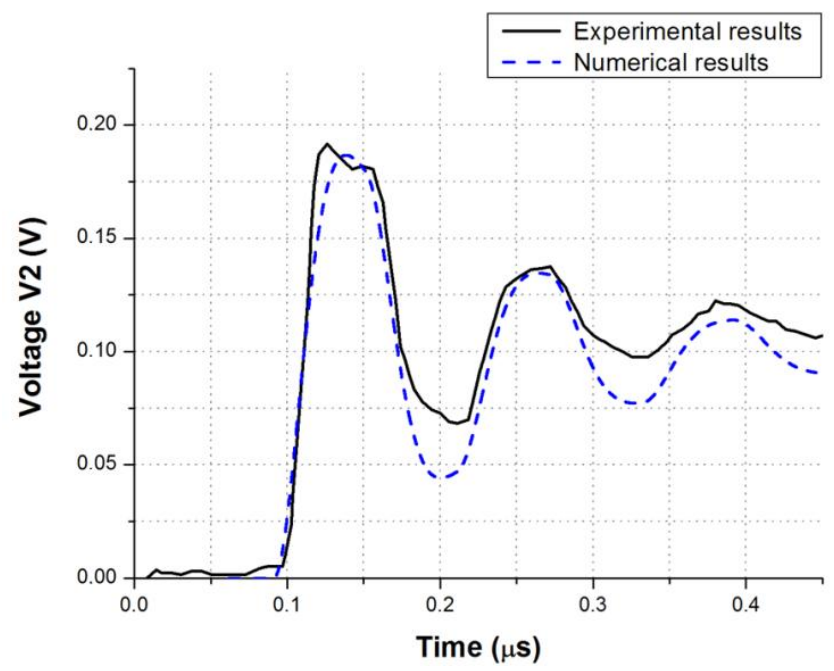


Fig.17. Comparison between numerical and experimental waveforms of voltage V2, obtained via FDTD simulation (this work) and measurements performed in [28].

It is observed that the simulated voltage is not completely identical to the experimental result. This occurs because the exact dimensions of width and thickness of the experimental bar are not given in [28]. However, the two results present very close phases and amplitudes. Therefore, one can state that adequate qualitative and quantitative agreements are obtained. This validates the method and the developed software used for simulating the present problem.

\section{APPENDIX B: NUMERICAL EVALUATION OF CURRENT COUPLING FACTOR FOR THE DIRECTIONAL COUPLER OVER THE ROEBEL BAR}

In order to determine the current coupling factor between the Roebel bar and the designed directional coupler, we have simulated the problem depicted in Fig. 18. For this aim, the numerical problem defined on Fig. 6 has been adapted as follows: 1) the excitation source has been replaced by a PD source positioned inside the Roebel bar insulation; 2) as long as current coupling factor is to be calculated, we have included a $50 \Omega$ load resistor connected to the directional coupler port for maximizing power transferring. All remaining simulation parameters were preserved.

At this point, it is important to notice that because the electromagnetic waves originated at PD excitation point reflect at the bar ends, partial discharge signals can be detected by the directional coupler regardless of the position of PD source. For this reason, directional coupler can be installed parallell to the bar with any of the two possible orientations, as it is shown, for example, in Fig.18.

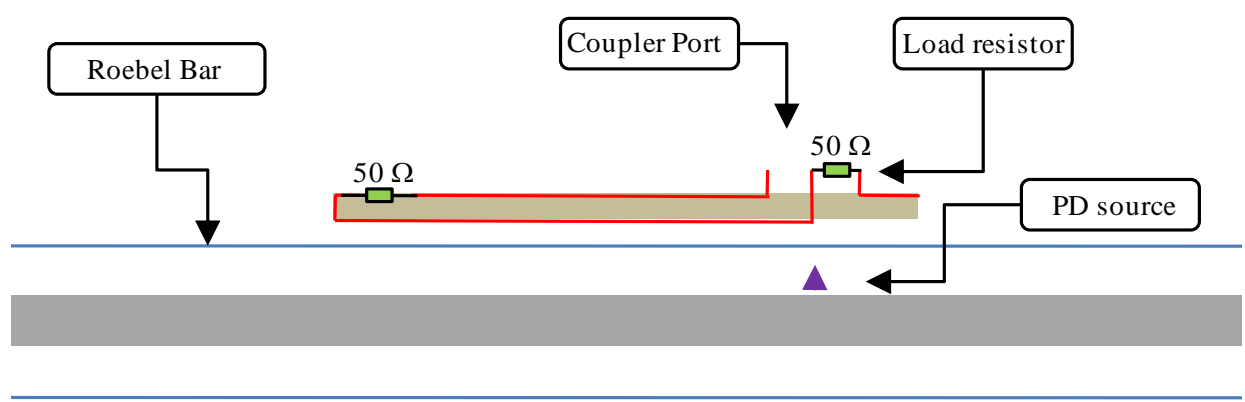

Fig.18. Schematics of the numerical setup conceived for calculating the current coupling factor between the Roebel Bar and the microstrip direction coupler. The bar and the coupler are separated by a single FDTD cell.

Transient currents $i_{P D}(t)$ and $i_{L}(t)$ were calculated, respectively, at the PD excitation point and across the load resistor (Fig. 18). In order to obtain the coupling factor $C_{f a c t}$ as a function of frequency $f$, we have computed the following expression 


$$
C_{\text {fact }}(f)=10 \log _{10}\left(\frac{\mathfrak{J}\left\{i_{L}(t)\right\}}{\mathfrak{J}\left\{i_{P D}(t)\right\}}\right)
$$

for several frequencies from $1 \mathrm{kHz}$ to $2 \mathrm{GHz}$. In (2), the symbol $\mathfrak{I}$ indicates the fast Fourier transform (FFT). The obtained curve for $C_{f a c t}(f)$ is given in Fig. 19.

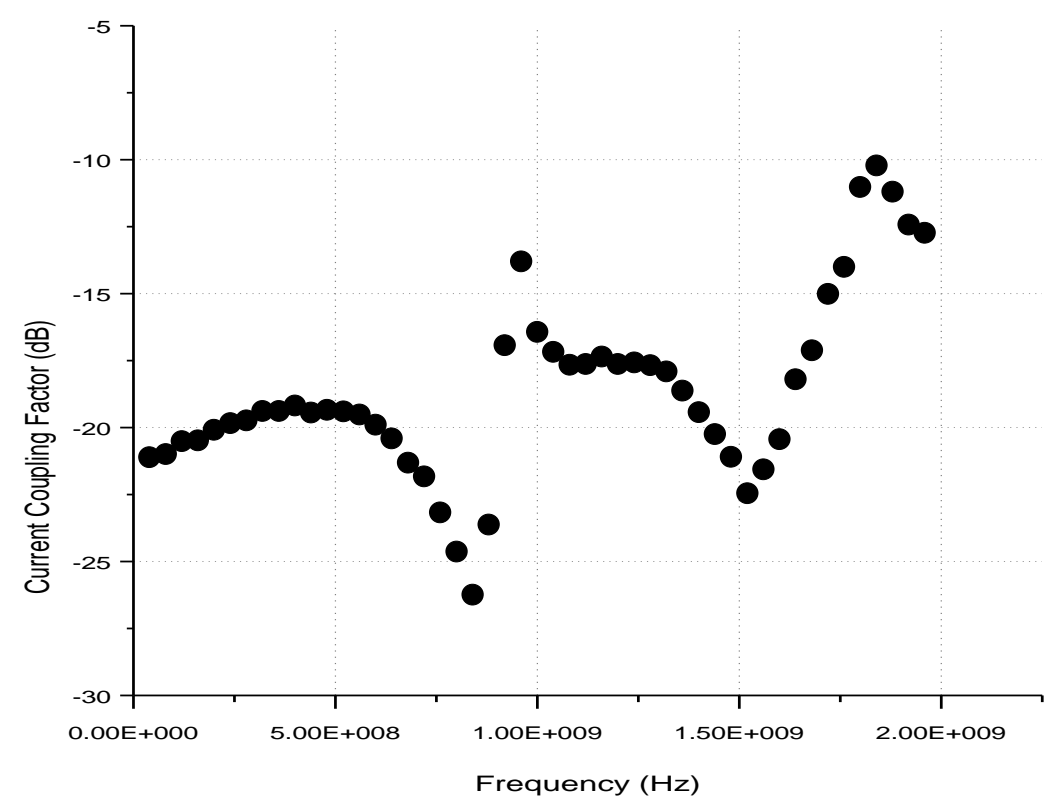

Fig.19. Current coupling factor between the Roebel Bar and our microstrip direction coupler.

We see in Fig. 19 that the current coupling factor ranges from approximately $-27 \mathrm{~dB}$ to $-10 \mathrm{~dB}$ over the frequency band of interest. Notice that the resonances observed at approximately $990 \mathrm{MHz}$ and $1800 \mathrm{MHz}$ are consistent with the data shown in Fig. 5.

\section{ACKNOWLEDGMENTS}

The authors would like to thank Eletronorte for financial and laboratorial support. We also would like to thank Prof. Dr. Gervásio Cavalcante and Eng. Miércio Alcântara for allowing us to use their UHF measurement equipment.

\section{REFERENCES}

[1] G.C. Stone, "A Perspective on Online Partial Discharge Monitoring for Assessment of the Condition of Rotating Machine Stator Winding Insulation”, IEEE Electrical Insulation Magazine, Vol. 28, No. 5, pp. 8-13, 2012.

[2] Institute of Electrical and Electronic Engineers, "Guide to Measurement of Partial Discharge in Rotating Machinery", IEEE Std 1434, USA, 2000.

[3] International Electrotechnical Commission, "Rotating Electrical Machines - Part 27-2: On-line Partial Discharges Measurements on the Stator Winding Insulation of Rotating Electrical Machines", IEC 60034-27-2, March, 2012.

[4] International Electrotechnical Commission, "Rotating Electrical Machines - Part 27: Off-line Partial Discharges Measurements on the Stator Winding Insulation of Rotating Electrical Machines", IEC TS 60034-27, 2006.

[5] International Electrotechnical Commission, "High-voltage Test Techniques-Partial Discharge Measurement", IEC Publication-60270, Third Edition, 2000. 
[6] G.C. Stone, and V. Warren, "Differences in Stator Winding Partial Discharge Activity between Manufacturers". Iris Power Engineering, 1 Westside Drive, Unit 2 Toronto, Ontario, Canada M9C 1B2, 2005.

[7] Conseil International des Grands Réseaux Électriques, "Survey of Hydrogenerator Failures", CIGRÉ 392 - Working Group A1.10, 2009.

[8] M. Kurtz, “A partial discharge test for generator insulation,” Ontario Hydro Res. Q., vol. 25, no. 4, pp. 1-4, 1973.

[9] G.C. Stone, "A Perspective on Online Partial Discharge Monitoring for Assessment of the Condition of Rotating Machine Stator Winding Insulation”, IEEE Electrical Insulation Magazine, Vol. 28, No. 5, pp. 8-13, 2012.

[10] IEEE Power \& Energy Society - Electric Machinery Committee, "IEEE Guide for the Measurement of Partial Discharges in AC Electric Machinery", IEEE P1434/D1.1, 2010.

[11] S.R. Campbell, G.C. Stone, H.G. Sedding, "Application of pulse width analysis to partial discharge detection," in IEEE International Symposium on Electrical Insulation, 1992, pp. 345-348.

[12] H.G. Sedding, S.R. Campbell, G.C. Stone, G.S. Klempner, "A new sensor for detecting partial discharges in operating turbine generators," IEEE Transactions on Energy Conversion, vol.6, no.4, pp.700-706, Dec. 1991.

[13] G.C. Stone, H.G. Sedding, N. Fujimoto, and J.M Braun, "Practical Implementation of Ultrawideband Partial Discharge Detectors," IEEE Transactions on Electrical Insulation, Vol. 27, No. 1, 1992.

[14] K. Yee, "Numerical solution of initial boundary value problems involving Maxwell's equations in isotropic media," IEEE Transactions on Antennas and Propagation, vol. 14, no. 3, pp. 302 -307, may 1966.

[15] A. Taflove and S. Hagness, Computational Electrodynamics: The Finite-Difference Time-Domain Method, $3^{\text {rd }}$ ed., Artech House, 2005.

[16] J.A. Roden and S.D. Gedney, "Convolution PML (CPML): An efficient FDTD implementation of the CFS-PML for arbitrary media", Microwave and Optical Technology Letters, vol. 27, No 5, pp. 334-339, Dec. 2000.

[17] A. Svatik, V. Adamec and J.H. Calderwood, "Dielectric properties of epoxy/mica insulation," in Fifth International Conference on Dielectric Materials, Measurements and Applications, Jun 1988, pp.262-265.

[18] P.J. Moore, I. Portugues, and I.A. Glover, "A non-intrusive partial discharge measurement system based on RF technology," in Proc. IEEEPower Eng. Soc. Gen. Meeting, vol. 2, 2003, pp. 628-633.

[19] T. Ozaki, K. Abe, and T. Umemura, "Partial discharge detection using ferrite antenna," presented at the IEEE Int. Symp. Electr. Insul., Jun. 1992, Baltimore, MD.

[20] H. Muto, Y. Kaneda, H. Aoki, O. Hamamoto, "On-line PD Monitoring System for Rotating Machines using Narrow Band Detection of EM Wave in GHz Range", in Proc. of International Conference on Condition Monitoring and Diagnosis (CMD 2008), Beijing, 2008, pp. 1093-1096.

[21] R.M.S. de Oliveira, C. Sobrinho, "Computational Environment for Simulating Lightning Strokes in a Power Substation by Finite-Difference Time-Domain Method," IEEE Transactions on Electromagnetic Compatibility, vol.51, no.4, pp.995-1000, Nov. 2009.

[22] A. Eroglu and J. K. Lee, "The Complete Design of Microstrip Directional Couplers Using the Synthesis Technique", IEEE Transactions on Instrumentation and Measurement, vol. 57, no. 12, December 2008.

[23] H. C. Cheng and R. V. Ramaswamy, "Determination of the coupling length in directional couplers from spectral response", IEEE Photonics and Technology Letters, vol. 2, no. 11, Nov. 1990.

[24] T. Noda, A. Tatematsu and S. Yokoyama, "Improvements of an FDTD-based surge simulation code and its application to the lightning overvoltage calculation of a transmission tower", in International Conference on Power Systems Transients, 2005, Montreal, Canada.

[25] T. Sterling, D. J. Becker, D. Savarese, J. E. Dorband, U. A. Ranawake, and C. E. Packer. "Beowulf: A Parallel Workstation for Scientific Computation,” in Proceedings of the International Conference on Parallel Processing 95, 1995.

[26] D.M. Sheen; S.M. Ali; M.D. Abouzahra; Jin-Au Kong, "Application of the three-dimensional finite-difference timedomain method to the analysis of planar microstrip circuits," IEEE Transactions on Microwave Theory and Techniques, vol.38, no.7, pp.849, 857, Jul. 1990.

[27] H.A. Weeler, "Transmission-line properties of a strip on a dielectric sheet on a plane", IEEE Trans. on Microwave Theory and Techniques, vol. 25, no. 8, pp. 631-647, Aug. 1977.

[28] O. Lesaint, T. Lebey, S. Dinculescu, H. Debruyne and A. Petit, "Propagation of fast PD signals within stator bars performance and limitations of a high frequency monitoring system," in Proceedings of the 7th International Conference on Properties and Applications of Dielectric Materials, vol. 3, 2003, pp. 1112-1115.

[29] G.C..Stone, "Partial discharge diagnostics and electrical equipment insulation condition assessment," IEEE Transactions on Dielectrics and Electrical Insulation, vol.12, no.5, pp.891,904, Oct. 2005.

[30] G.C. Stone, V. Warren, "Objective methods to interpret partial-discharge data on rotating-machine stator windings," IEEE Transactions on Industry Applications, vol.42, no.1, pp.195-200, Feb. 2006. 
[31] A. Svatik, V. Adamec, and J. H. Calderwood, "Dielectric properties of epoxy/mica insulation," in Fifth International Conference on Dielectric Materials, Measurements and Applications, 1988, pp.262-265.

[32] F. T. Ulaby, Electromagnetics For Engineers, Prentice Hall, 2005. 